\title{
Psychological characteristics of internationally adopted post- institutionalized children with Fetal Alcohol Spectrum Disorders
}

\author{
Boris Gindis \\ Center for Cognitive/Developmental Assessment and Remediation, Airmont, New York/Phoenix, Arizona, United States
}

\begin{abstract}
Aims: Fetal Alcohol Syndrome Disorder (FASD) is widely observed in internationally adopted (IA) post-institutionalized children. The specificity of FASD in IA children has significant practical implications and necessitates a modified methodology for identification and remediation.

Design methods, and participants: Clinical case study with statistical analysis (simple frequency recorded in an Excel spreadsheet); quantitative and qualitative data was obtained through individual medical, neuropsychological, and educational assessments of 63 children, ages five to sixteen, adopted from Eastern Europe to the United States.

Findings: FASD in international adoptees presents amplified characteristics typical for this condition, with the following specificities revealed in our research: rapid first-language loss and a particular pattern of English language learning; profound complex childhood trauma related to extreme deprivation and institutional upbringing; "mixed maturity" evident in impaired executive functions; low predictive accuracy during a pre-adoption screening for FASD conditions; general cognitive ability (IQ) being in the Low Average to Borderline range, with processing speed, attention, and working memory as the weakest cognitive skills; and academic achievements being higher than could be predicted based on cognitive abilities.

Conclusions: FASD must be recognized as an educational handicap in our school system in order to change the outcomes for afflicted children. Educational remediation and cognitive-behavioral therapeutic intervention are the most effective remedial methods for IA children with FASD. Practical recommendations for adoptive parents include early identification and specialized remediation of "secondary" disabilities through concerted efforts of the school and family.
\end{abstract}

International adoption is a fact of life in the United States: the U.S. Bureau of Consulate Affairs reports that over half a million entry visas were issued from 1990 to 2012 to orphans born overseas and adopted into American families (U.S. Department of State, Office of Children's Issues, 2013). According to statistics from the U.S. Department of State's Office of Children's Issues (2012), in fiscal years 1996 to 2012, over 106,000 adoptees arrived from former Soviet republics, mostly from Russia, Ukraine, and Kazakhstan.

This group of international adoptees has a higher incidence of FASD than do children adopted from other regions of the world (Aronson, 2000; Landgren, Svensson, Strömland, Andersson, \& Grönlund, 2010; Miller, 2005, Miller, Chan, \& Litvinova, 2006; Robert et al., 2009). Unfortunately, the current statistics on FASD in this group are unreliable due to different standards used to define FASD, but a review of publications in the U.S., Canada, and Western Europe suggest that by a conservative estimate, the share of children adopted from the former Soviet Union who have full-fledged FASD conditions approaches 10 percent (Welsh, Andres, Viana, Petrill, \& Mathias, 2007).

\section{Study design and methodology}

Thus far, there has been no systematic and focused psychoeducational assessment of FASD characteristics among adoptees from Eastern Europe. This article addresses this issue from a mental health and educational perspective. The goal of the study was to determine the specificity of IA children with FASD against, on one hand, non-adopted children in the US and Canada afflicted with FASD, and, on the other hand, IA children with the same background and demographic characteristics but without FASD. The specificity of IA children with FASD may suggest the most effective means of remediation for this group.

Quantitative and qualitative clinical data were collected at the Center for Cognitive and Developmental Assessment and Remediation, located in New York and Arizona (www.bgcenter.com). This non-governmental clinic specializes in working with internationally adopted postinstitutionalized children and their families.

Correspondence: Boris Gindis, Ph.D., Chief Psychologist, Center for Cognitive/Developmental Assessment and Remediation, 13 South Van Dyke Ave., Airmont, NY 10901. Telephone/Fax: 1-845-533-4300. E-mail: gindis@bgcenter.com

Keywords: FASD, FAS, internationally adopted children with FASD, neuropsychological profile of children with FASD, educational profile of children with FASD,

FASD as an educational handicap, Fetal Alcohol Syndrome in adopted children, FAS in children adopted from Russia 
Clinical data were obtained through medical, neuropsychological, and educational assessments of 63 children aged five to sixteen adopted from Eastern Europe. Simple frequency analysis was recorded in an Excel spreadsheet.

Following the study design, the control group was composed of internationally adopted children in the Center's database who do not have FASD: 489 cases matched by age, gender, country of origin, and adoption age. Another "control group" was non-adopted children diagnosed with FASD, as reflected in a comprehensive research literature review by Matson, Crocker, and Nguyen (2011).

Fetal Alcohol Spectrum Disorder (FASD) is defined as a category of static encephalopathy with a known teratogen: alcohol. In this study a team of two specialists, a medical doctor and a licensed psychologist, established diagnoses of FASD. Using the 4-Digit Diagnostic Guide for Fetal Alcohol Spectrum Disorders, 3rd Edition (Astley, 2004), including computer-based facial features analysis (Astley \& Clarren, 1996), only children who fulfilled the following FASD criteria were selected for the study:

1. Growth deficiency (post-natal height and weight at or below the 10th percentile).

2. FASD facial features (all three characteristics of FASD facial phenotype present).

3. Central nervous system damage (clinically significant structural, neurological, and functional impairments are to be defined).

4. Prenatal alcohol exposure confirmed or judged "likely, but not properly documented.”

All members of the group exhibited FASD facial phenotypes: palpebral fissure length, upper lip circularity, and philtrum smoothness to a significant degree: level $\mathrm{C}$ according to the 4-Digit Diagnostic Guide Manual (4DDG). Microcephaly-head circumference below the 10th percentile for the respective age group-was found in nearly half the group (31 out of 63), with 16 children (25\%) having head circumference below the third percentile. All members of the group had growth deficiency in height (over one-third were below the third percentile, the rest were below the 10th percentile for their age group); in weight (half of the group were below the third percentile, the rest were below the 10th percentile); and in head circumference (16\% of the group fell below the third percentile, the rest were between the 10th and 50th percentile)-level C and D (moderate to severe degree of FASD presence), according to 4-DDG. As presented below, all members of the cohort had significant functional impairments, reflected in cognitive, emotional, educational, and self-regulatory issues.

Documented histories of prenatal alcohol exposure are practically absent in medical or legal documentation related to international adoption. Current research on FASD (Barth \& Brooks, 2000) indicates that nine out of 10 international adoptees with FASD do not have documented evidence of the biological mother's heavy drinking during pregnancy. In our group, all 63 participants were "social orphans," placed in an orphanage after their parents -in $92 \%$ of cases, single mothers-were deprived of their parental rights due to child neglect and abuse. In adoptionrelated court documentation, abuse of alcohol was cited as a "standard feature" of mothers unfit to parent a child. However, the mothers were described as "registered alcoholics," following mandatory treatment before the child's birth, in only four out of 63 cases. For the remainder, Western standards of "documented drinking" (as presented in Astley, 2004) are not applicable.

Table 1

Demographic and statistical data

\begin{tabular}{ll}
\hline Parameters & Descriptive information \\
\hline $\begin{array}{l}\text { Overall number of subjects } \\
\text { Countries of origin }\end{array}$ & 63 \\
& $\begin{array}{l}\text { Russia (72\%), Ukraine (18\%), Kazakhstan (5\%), Moldova (1 person), Estonia (1 } \\
\text { person), Latvia (1 person). } \\
27 \text { girls (42\%) and } 36 \text { boys (57\%). }\end{array}$ \\
Gender & $\begin{array}{l}\text { From } 5 \text { years to } 16 \text { years } \\
\text { Chronological age at the time of assessment }\end{array}$ \\
$\begin{array}{l}\text { Fdoption age (time in the family) } \\
\text { Bilingual factor }\end{array}$ & $\begin{array}{l}6 \text { out of } 63 \text { assessments were bilingual: evaluation was conducted in Russian } 9 \text { years; median age } 4 \text { years and } 8 \text { months. } \\
\text { and English. }\end{array}$ \\
Longitudinal component & $\begin{array}{l}15 \text { out of } 63 \text { cases are longitudinal: from } 2 \text { to } 6 \text { consecutive assessments within } 3 \\
\text { to } 9 \text { years. }\end{array}$ \\
\hline
\end{tabular}


Clinical case studies included assessments of:

- general cognitive ability (IQ), measured by the WISCIV and, in six cases, by non-verbal assessment through Universal Non-Verbal Intelligence Tests (UNIT)

- specific cognitive processes, such as speed of processing and working memory, measured by means of “cross-battery approach” (McGrew, Ortiz, \& Flanagan, 2001) using relevant subtests from UNIT, NEPSY-II, WJ-III, Cognitive, and WISC-IVIntegrated

- educational achievement, measured by the WJ-III, Achievement Tests, Normative Update

- adaptive behavior, measured by Adaptive Behavior Assessment Scale-II (ABAS-II)

- executive functions assessed through Behavior Rating Inventory of Executive Functions (BRIEF), selected tests from NEPSY-II and Neurocognitve Assessment Battery.

The psycho-educational profile of internationally adopted children with FASD discussed in this article is presented in three modalities: general cognitive ability (IQ), adaptive behavior (SQ), and educational achievement. In each modality, a specific component was selected for further investigation. In general cognitive ability, this component was processing speed and working memory; in adaptive behavior: executive functions; and in educational achievement: math. These components were selected due to the availability of extensive research literature and the opportunity to compare our findings with existing data obtained in the population at large (children of the same age range) with FASD.

\section{Findings}

In our sample, as presented in the graph below, general cognitive ability was in the range of 76 to 92 , with an average score of 82 (Low Average to Borderline range). Composite adaptive behavior standard scores fell in the range of 67 to 80, with an average score of 75 (Borderline range). Total achievement standard scores were in the 82 to 96 range, with an average score of 91 (Average to Low Average range).

Processing speed measurements revealed a rather wide range (77 to 109), with the arithmetical average of 93 being somewhat unrepresentative. The majority of examinees performed close to their respective age norms (mostly in the Low Average to Average range) in simple graphomotor tasks like Visual Matching (WJ-III, Cognitive) or Coding (WISC-IV). However, for more cognitively demanding assignments that depended on the application of speedy and accurate high-order reasoning in a systematic goal-directed behavior (e.g., Cancellation in WISC-IV or Decision Speed in WJ-III), the outcome was far below average for age expectations. Working memory, like processing speed, fell within a broad range of standard scores, from 72 to 99 , with an average of 85 . Standard scores in executive functions, on the other hand, were in the rather narrow range of 60 to 74, with an average of 67.

\section{Figure 1}

\section{Basic psychological functions}

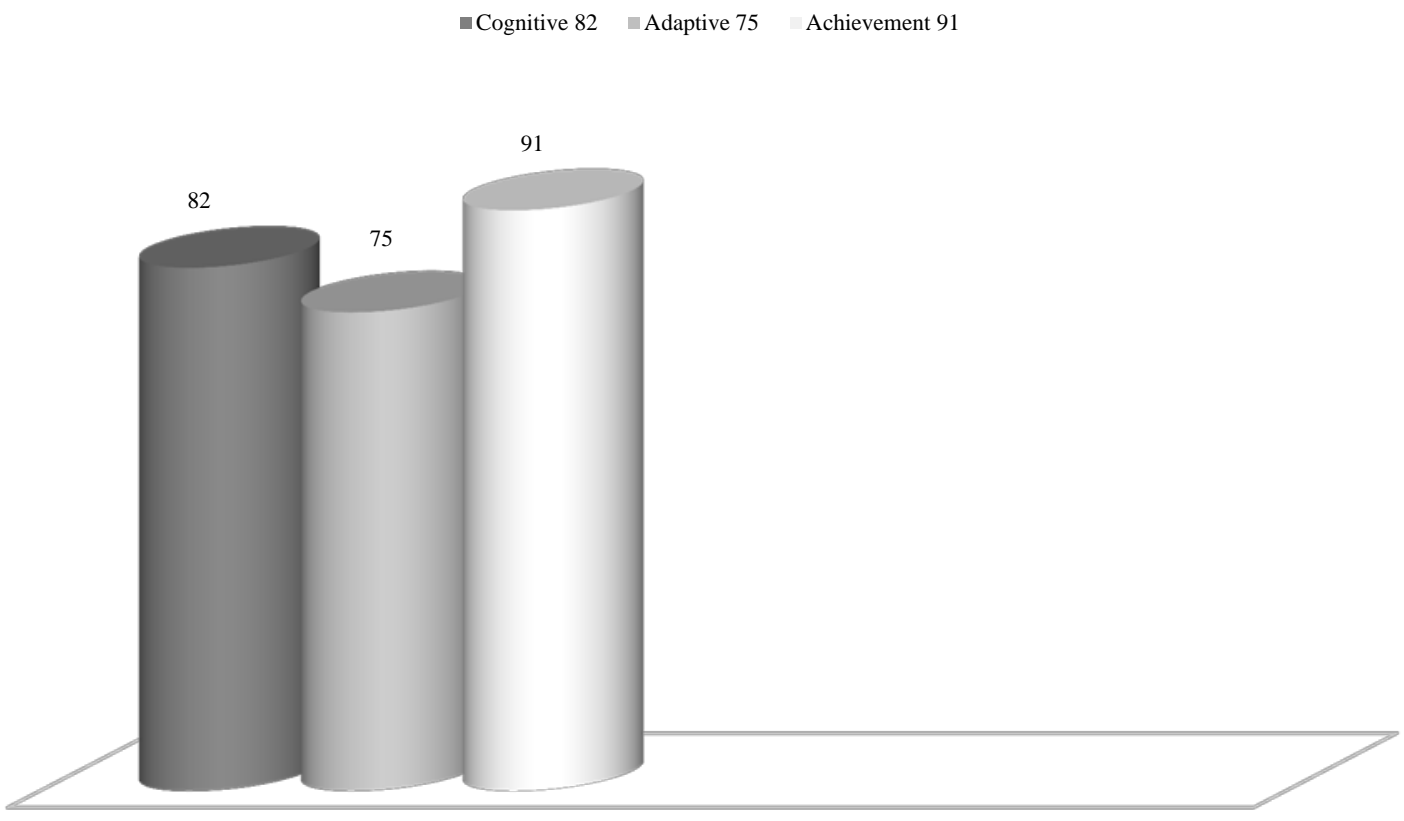




\section{Figure 2}

\section{Specific psychological function}

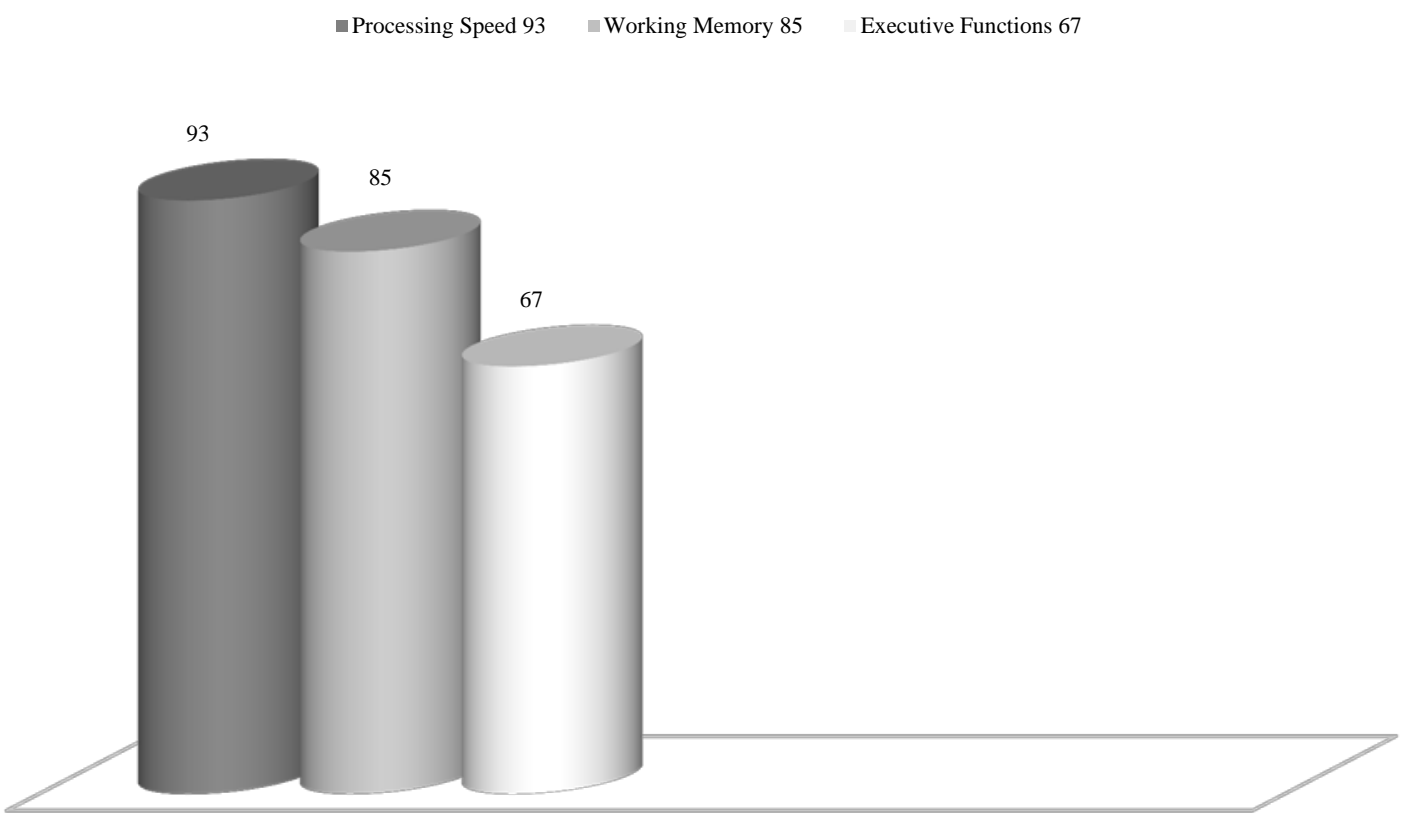

\section{Interpretation}

In the FASD-diagnosed population at large, a significant number of children have mental retardation (Pulsifer, 1996). In our sample of international adoptees with unambiguous FASD conditions, there were no children with mental retardation. The selection process during international adoption may account for this: children with known mental retardation are less likely to be chosen for adoption.

Research literature identifies slow processing speed (Burden, Jacobson, \& Jacobson, 2005), limited attention (Burden, Jacobson, Sokol, \& Jacobson, 2005), restricted working memory (Rasmussen, 2005), and difficulties with high-order reasoning in school-age children with FASD conditions (McGee, Bjorkquist, Price, Mattson, \& Riley, 2009). Our data only partially confirms these findings. We found that the composite cognitive profile of children in our cohort, obtained by major standardized test batteries, is diverse, complex, and subject to individual differences. Analysis of clinical data allows us to make the following observation on the specificity of cognitive functioning of IA children afflicted with FASD:

IA children with FASD can show close-to-age-expectation processing speed, attention capacities, and functional working memory in structured individual testing situations and when given simple tests on processing speed, attention, and working memory. However, in tests where selfregulation of cognitive processes required goal-directed systematic performance, scores lowered almost uniformly. Our subjects demonstrated distinct difficulties in regulating attention and sustaining attention in a goal-directed activity. It appears that limitations in cognitive functioning can be found outside of cognition itself, in limited ability to selfregulate cognitive processes.

The dynamic of cognitive development in IA children with FASD also has its specificity. A number of longitudinal research reports (following the same subjects for six to twenty years) have concluded that individuals with FASD tend to score lower on IQ tests and attain lower academic achievements as they progress into early adulthood. The researchers term this phenomenon "deterioration" (Matson et al., 2011). Our data suggest a different explanation.

Our longitudinal group consisted of 15 cases subjected to comprehensive psycho-educational evaluations from three to six times within nine years. As time progressed, this longitudinal group consistently scored lower and lower on cognitive and academic tests. However, this should not be termed "deterioration." In fact, the subjects had progressed and continue to do so, but at a slower pace than their peers at large. As a result, it may appear they are deteriorating. Individuals with FASD are known to have problems with high-order (abstract) reasoning (Matson et al., 2011; McGee, Schonfeld, Roebuck-Spencer, Riley, \& Mattson, 2008). In early elementary school this is not as obvious and they can make it through those years without noticeable differences. After the age of 12, however, both cognitive tests and academic assignments rely more heavily on abstract thinking. At this point, students with FASD begin to fall behind norms designed for their nonhandicapped peers. While IA children with FASD present 
a range of cognitive abilities, most fall in the Low Average/Borderline category; as academic and psychological tests become more complex and abstract in nature, those in the Low Average range struggle and tend to slide into the Borderline range of general cognitive ability. This may produce the impression of "deterioration," but in fact it is a specific and typical dynamic of cognitive/academic functioning for individuals with FASD: the pace of their cognitive development does not conform to societal expectations for certain age groups.

Adaptive behavior is the lowest scoring function in our sample. Qualitative analysis shows the following pattern: while activities in the Practical domain were mostly within the Average to Low Average range in relation to age norms and expectations, the Conceptual and Social domains were well below expectations. The key component of successful adaptation to an environment is self-regulation of behavior and emotions. In this respect, our group showed significant deficiencies: their average Global Executive Composite (consisting of Behavior Rating Index and Meta-Cognitive Index) standard score, as measured by the BRIEF, is 72-at or below the third percentile in comparison with their nonhandicapped peers. Immature self-regulation of cognitive and behavioral aspects of life in IA children suffering from FASD is determined by the specificity of brain damage related to alcohol (Green et al., 2009; Gunnar \& Van Dulmen, 2007; Matson et al., 2011). However, we should not underestimate social and cultural factors in developing this disability. Lack of adult-mediated learning, modeling, and opportunities to imitate and practice self-regulation in an institutional setting, as well as inadequate remedial efforts after adoption, may substantially aggravate the situation (Gindis, 1998). For IA children with FASD, institutional rearing is a dual predicament: this system can only reinforce the neurological impairment of their central nervous system, taking poor self-regulation to extremes.

\section{The "reverse discrepancy" phenomenon in international adoptees with FASD}

The "discrepancy formula," well-known in educational domains, attempts to identify students' learning disabilities by detecting a statistically significant and clinically meaningful discrepancy between IQ scores and achievement scores (Henley, Ramsey, \& Algozzine, 2009). It was found that the achievement scores for the majority of children in our sample (82\%) were higher than their cognitive scores. This phenomenon could be called a "reverse discrepancy formula." In other words, IA students with FASD performed better academically than could be predicted from their cognitive performance. An explanation for this rather unique phenomenon seems to be strong family support and remedial efforts at school focused on academic achievements rather than cognitive skills. IA children with FASD can do better in school than may be expected based on their IQ scores: a cognitive profile per se may not be a reliable and valid predictor of their academic functioning.

Analysis of our group's standard test scores (WJ-III, Achievement, Normative Update) shows that oral cognitive/academic language (both receptive and expressive modes) and reading were relative academic strengths, while math was a distinct weakness. Practically all aspects of functional math skills-calculation, word problem solving, fluency, and quantitative reasoningpresented the children with marked difficulty. Further investigation is necessary to determine why math presents more academic difficulties than do reading or writing.

\section{Characteristics of "secondary" disabilities in internationally adopted children with FASD}

The term "secondary" disability was initially introduced by Lev Vygotsky in the late 1920s; it refers to distortions of higher psychological functions in disabled individuals resulting from social factors (Vygotsky, 1931/1993). As explained by Vygotsky, organic impairment prevents children from mastering cognitive, social, and academic skills at an age-appropriate rate and level. Progressive divergence from social and natural milestones of development leads to social deprivation in the form of exclusion, humiliation, segregation, and so forth. This, in turn, adversely affects the entire developmental process and leads to delays and deficiencies that are not directly related to organic impairment, but rather to societal treatment. From this perspective, many psychological characteristics of FASD are secondary defects acquired in the process of socialization. As convincingly shown by Streissguth, Barr, Kogan, and Bookstein (1996), FASD may lead to such secondary disabilities as emotional and behavioral disorders (e.g., depression or conduct disorder), disrupted formal schooling due to behavior problems, violations of law, promiscuity, and alcohol/substance abuse.

Secondary disabilities are common in all children with FASD; however, children adopted internationally have often been exposed to an adverse social environment that reinforces the emergence of secondary disabilities (Gindis, 1998). While children with FASD born in the U.S. may be exposed to remediation at an early age, children with FASD adopted internationally typically do not have such opportunities. Therefore, adoptive parents and mental health professionals have to deal with primary organic impairment as well as with acquired and enhanced secondary disabilities. Further, a secondary disability can be augmented by the loss of native language and difficulties with social adjustment to a foreign culture (Gindis, 2006, 2008a). Taken together, the social and cultural changes related to international adoption can cause more pronounced secondary disabilities in IA children; this must be clearly recognized and appropriately addressed by adoptive parents and society at large.

\section{"Language lost-language found" experience in international adoptees with FASD}

Abrupt native language attrition and a specific dynamic of new language learning are characteristic of all international adoptees (Gindis, 1999, 2008a). The native language loses its functionality upon arrival in a new country and attrition starts immediately. It is faster with young children, but even in "older adoptees" (age five and up) this process takes somewhere from several months to about two years 
(Gindis, 2006, 2008a). Learning a new language (English) happens alongside swift first-language loss, in accordance with the circumstantial subtractive second-language learning model (Gindis, 2006). While the communicative aspect of the new language can be functional within the first year in a new motherland, the cognitive/academic aspect of that language will not be fully mastered for several years to come. In children with FASD, this process is even more complex: it is manifested in numerous social and learning problems, showcasing cognitive weaknesses and amplifying emotional and behavioral issues to the extreme. All three major functions of languagecommunication, behavior regulation, and cognitive operations - are weaker in individuals with FASD, but in IA children, this weakness is magnified by abrupt native language attrition and the slow acquisition of their new language. This leads to numerous social and academic problems that must be properly understood and addressed by educators and adoptive parents.

\section{Social and emotional factors as a major contributor to secondary disability in IA children with FASD}

The most significant factor leading to secondary disabilities in IA children with FASD is complex childhood trauma. Emotional fragility, dis-regulated emotions, and low tolerance for frustration are the "trademarks" of internationally adopted post-institutionalized children (Gindis, 2006, 2008b). Emotional vulnerability and instability are the consequences of multiple traumatic life events and make these children prone to Developmental Trauma Disorder (DTD), Post-Traumatic Stress Disorder, and Dis-regulated Mood Disorder (Nemeroff, 2004; Perry, 2006; Rolnick, 2010; Van der Kolk, 2005).

During the intake interview, all adoptive parents in our study completed the Developmental Trauma Disorder Questionnaire - a list of 15 probable events and life circumstances that their children might have experienced in pre-adoption life. Each of these events or life conditions could objectively be a trauma-producing agent. It is important to emphasize the repetitive, recurring nature of trauma in internationally adopted post-institutionalized children. Such a chain of trauma-producing events includes, but is not limited to, abandonment and/or repeated desertion during early childhood; extreme physical discomfort (e.g., hunger, cold, dehydration, etc.), combined with a profound neglect of basic physical and emotional needs; physical abuse; sexual abuse or exposure to inappropriate sexual scenes; witnessing violence; placement in an institution, such as a hospital or orphanage, and transfer between institutions; various abuses by peers, ranging from bullying to rape; repeated separation from caregivers due to multiple placements; failed adoption or foster care attempts; and finally, adoption to a foreign country, which leads to sudden loss of language, culture, and physical environment.

As revealed in research (Van der Kolk, 2003) and confirmed by clinical practice, Developmental Trauma Disorder (DTD) adversely affects maturation by inhibiting the integration of cognitive, emotional, and sensory functions into a cohesive whole. The victims of DTD present "mixed maturity": in some circumstances they behave like someone much younger, and in other situations, someone much older. Their reactions to social events, interpersonal relationships, academic learning, and overall adaptive behavior often do not match expectations for children their age (Gunnar \& Van Dulmen, 2007; Hyter, 2012)

One of the most typical features in the emotional make-up of a child with DTD is hyper-arousal. Traumatic events have the capacity to change the CNS of children and keep it in a prolonged aroused state; every perceived threat reinforces the sensitized neuronal pathways for fear/stress response, causing immature, aggressive, and socially inappropriate responses to routine family/school events (Perry, 2006). Research related to emotional trauma in children with FASD conditions shows that trauma has a generalized negative impact on most psychological functions, such as language, memory, visual processing, motor skills, and attention (Henry, Sloane, \& Black-Pond, 2007; Hyter, 2012). The most deficient area of functioning in our sample, when compared with international adoptees of analogous age and gender without FASD, was selfregulation of emotional states, mostly in the form of hyperarousal. Because of their emotional fragility, internationally adopted post-institutionalized children with FASD are more vulnerable to mismatches between their academic readiness and level of instruction; they are less robust in their ability to withstand the stress related to school performance and are less self-sufficient in overcoming the emotional strain associated with a competitive school environment. Their emotional fragility constitutes an educational impediment.

In the school context, social/emotional functioning is as important as academic achievements. As reported by parents and teachers, IA children with FASD conditions lack behavioral control, are prone to misinterpreting social conventions, and/or have difficulty understanding causeeffect relationships. Parents and teachers are united in their perception of IA children with FASD as a socially immature group in comparison with their peers. Often these children do not realize the implications of their actions for others. Many IA children with FASD are naïve and overly friendly, which may make them vulnerable to predatory adults. IA children with FASD conditions require more control and supervision than do other children their ages.

\section{Remediation: IA children with FASD in our school system}

The goals of family-based upbringing and school-based education for IA children with FASD are to fully acclimate them to a new language and a new social and cultural environment; to remediate, as much as possible, their secondary disabilities in social spheres; and to educate them so they can function in modern society. These goals can be achieved only through a long process of maturation, socialization, and teaching and learning using appropriate remedial methodologies (Paley \& O’Connor, 2009; Welsh 
et al., 2007). Timing and intensity are crucial factors for well-planned remediation. Early detection of FASD is vital because it allows for early intervention which may reduce secondary disabilities. The first line of defense for adoptive parents of children with FASD is school-based educational support and psychological services. A parent may ask a family physician for pharmacological intervention for certain symptoms (e.g., impulsivity or debilitating anxiety), but the main partners in remediation should be a teacher and a psychologist. Educational and therapeutic interventions are the only known means of rehabilitation for FASD.

As a medical condition, FASD is similar to disabilities such as ADHD, child depression, severe asthma, and organic conditions with psycho-educational implications. In this respect, FASD must be recognized as an educationally handicapping condition. Afflicted children must receive an Individual Educational Plan that spells out educational needs and therapeutic interventions; they must have a transitional plan upon entering high school. It is also imperative that adoptive parents are aware of FASD and are prepared for intensive and comprehensive remedial work with their child.

A full psychological evaluation is the first step in creating a remedial program. At school, IA students with FASD may qualify for special education services under the category "Other Health Impaired" (OHI). Some of these students may need as little as Resource Room support and schoolbased counseling. Some may need a self-contained placement and a number of services, including speech, OT, and specialized counseling. Still others may end up in Residential Treatment Centers or specialized day schools. FASD can manifest itself differently at different ages: from relatively manageable restlessness and inattentiveness in elementary school, to serious conduct issues during adolescence. A psychologist with a cognitive-behavioral background can help parents establish and manage a remedial environment at home and monitor their child's progress at school.

\section{Conclusion}

FASD in international adoptees presents an amplified picture of many characteristics typical for this medical condition in the population at large; at the same time, it has the specificity described above. Educational planning for IA children afflicted with FASD must take their emotional fragility into serious consideration. Educational professionals and parents have to walk a thin line, providing these students with intense and focused remediation while simultaneously being careful not to overwhelm them with unreasonable expectations and demands. Appropriate attitudes and expectations from adoptive parents are an important part of the remedial environment. IA children should not be exposed to the undue stress of facing a challenge that is beyond their actual readiness. Structure and consistency must be prominent elements of these children's support system: they have to learn self-regulation through direct and mediated learning.

\section{References}

Aronson, J. (2000). Alcohol-related disorders and children adopted from abroad. In R. Barth, M. Freundlich, \& D. Brodzinsky (Eds.), Adoption and prenatal alcohol and drug exposure: Research, policy, and practice (pp. 147171). New York, NY, United States: Evan B. Donaldson Adoption Institute and Child Welfare League Association.

Astley, S. (2004). Diagnostic guide for Fetal Alcohol Syndrome Disorders: The 4-Digit Diagnostic Code, 3rd edition. University of Washington, Seattle, WA, United States: FASD Diagnostic \& Prevention Network.

Astley, S., \& Clarren, S. (1996). A case definition and photographic screening tool for the facial phenotype for fetal alcohol syndrome. Journal of Pediatrics, 129, 3341.

Barth, R., \& Brooks, D. (2000). Adoption and prenatal alcohol exposure. In R. Barth, M. Freundlich, \& D. Brodzinsky (Eds.), Adoption and prenatal alcohol and drug exposure: Research, policy, and practice (pp. 2359). New York, NY, United States: Evan B. Donaldson Adoption Institute and Child Welfare League Association.

Burden, M. J., Jacobson, S. W., \& Jacobson, J. L. (2005). Relation of prenatal alcohol exposure to cognitive processing speed and efficiency in childhood. Alcoholism: Clinical and Experimental Research, 29, 1473-1483.

Burden, M. J., Jacobson, S. W., Sokol, R. J., \& Jacobson, J. L. (2005). Effects of prenatal alcohol exposure on attention and working memory at 7.5 years of age. Alcoholism: Clinical and Experimental Research, 29, 443-452.

Gindis, B. (1998, September and October). Navigating uncharted waters: School psychologists working with internationally adopted post-institutionalized children. NASP Communiqué, September (Part l) 27(1), 6, 9 and October (Part ll) 27(2), 20-23.

Gindis, B. (1999). Language-related issues for international adoptees and adoptive families. In T. Tepper, L. Hannon, \& D. Sandstrom (Eds.), International adoption: Challenges and opportunities (pp. 98-108). Meadow Lands, PA, United States: PNPIC. Retrieved from http://www.bgcenter.com/language.htm

Gindis, B. (2006). Cognitive, language, and educational issues of children adopted from overseas orphanages. Journal of Cognitive Education and Psychology, 4, 290315. Retrieved from http://www.iacep.coged.org

Gindis, B. (2008a). Abrupt native language loss in international adoptees. ADVANCE for Speech-Language Pathologists and Audiologists, 18, 5-13. Retrieved from http://speech-language-pathology-audiology.advance web.com/Editorial/Content/Editorial.aspx?CC=190870

Gindis, B. (2008b). Institutional autism in children adopted internationally: Myth or reality? International Journal of Special Education, 23, 118-123.

Green, C. R., Mihic, A. M., Nikkel, S. M., Stude, B. C., Rusmussen, C., Munoz, D. P., \& Reynold, J. N., (2009). Executive function deficits in children with fetal alcohol 
spectrum disorders (FASD) measured using the Cambridge Neuropsychological Tests Automated Battery (CANTAB). Journal of Child Psychology and Psychiatry, 50, 688-697.

Gunnar, M., \& Van Dulmen, M. (2007). Behavior problems in post-institutionalized internationally adopted children. Development and Psychopathology, 19, 129-148.

Henley, M., Ramsey, R., \& Algozzine, R. (2009). Characteristics and strategies for teaching students with mild disabilities (6th ed.). Upper Saddle River, NJ, United States: Pearson Education.

Henry, J., Sloane, M., \& Black-Pond, C. (2007). Neurobiology and neurodevelopmental impact on childhood traumatic stress and prenatal alcohol exposure. Language, Speech, and Hearing Services in Schools, 38, 99-108.

Hyter, Y. D. (2012). Complex trauma and prenatal alcohol exposure: clinical implications. Perspectives on SchoolBased Issues, 13, 32-42. Retrieved from http://div16perspectives.asha.org/content/13/2/32.full

Landgren, M., Svensson, L., Strömland, K., Andersson, M., \& Grönlund, U. (2010). Prenatal alcohol exposure and neurodevelopmental disorders in children adopted from Eastern Europe. Pediatrics, 125, 1178-1185.

Matson, S., Crocker, N., \& Nguyen, T. (2011). Fetal alcohol spectrum disorders: Neuropsychological and behavioral features. Neuropsychology Review, 21, 81101.

McGee, C., Bjorkquist, O., Price, J., Mattson, S., \& Riley, E. (2009). Social information processing skills in children with histories of heavy prenatal alcohol exposure. Journal of Abnormal Child Psychology. 37, 817-830.

McGee, C., Schonfeld, A., Roebuck-Spencer, T., Riley E., \& Mattson, S. (2008). Children with heavy prenatal alcohol exposure demonstrate deficits on multiple measures of concept formation. Alcoholism: Clinical and Experimental Research, 32, 1388-1397.

McGrew, K., Ortiz, S., \& Flanagan, D. (2001). Essentials of cross-battery assessment. New York, NY, United States: Wiley \& Sons.

Miller, L. (2005). The handbook of international adoption medicine: A guide for physicians, parents, and providers. Boston, MA, United States: Oxford University Press.

Miller, L., Chan, W., \& Litvinova, A. (2006). Fetal alcohol spectrum disorders in children residing in Russian orphanages: A phenotypic survey. Alcoholism: Clinical and Experimental Research, 30, 531-538.

Nemeroff, C. B. (2004). Neurobiological consequences of childhood trauma. Journal of Clinical Psychiatry, 65, 18-28.

Paley, B., \& O’Connor, M. J. (2009). Intervention for individuals with fetal alcohol spectrum disorders: Treatment approaches and case management. Developmental Disabilities Research Reviews, 15, 258267.

Perry, B. (2006). Childhood trauma, the neurobiology of adaptation and use-dependent development of the brain: How states become traits. Infant Mental Health Journal, 16, 271-291. Retrieved from http://www3.interscience. wiley.com/journal/112415976/
Pulsifer, M. B. (1996). The neuropsychology of mental retardation. Journal of the International Neuropsychological Society. 2, 159-176.

Rasmussen, C. (2005). Executive and working memory in fetal alcohol spectrum disorder. Alcohol Clinical Experimental Research, 29, 1359-1367.

Robert, M., Carceller, A., Domken, V., Ramos, F., Dobrescu, O., Simard, M. N., \& Gosselin, J. (2009). Physical and neurodevelopmental evaluation of children adopted from Eastern Europe. Canadian Journal of Clinical Pharmacology. 16, 432-440.

Rolnick, A. (2010). Persistent fear and anxiety can affect young children's learning and development. National Scientific Council on the Developing Child, Center on the Developing Child at Harvard University, Working Paper No. 9, 1-11. Retrieved from http://www.developingchild.harvard.edu.

Streissguth, A., Barr, H., Kogan, J., \& Bookstein, F. (1996). Understanding the occurrence of secondary disabilities in clients with fetal alcohol syndrome (FAS) and fetal alcohol effects (FAE): Final report to the Center for Disease Control and Prevention. Seattle, WA, United States: University of Washington, School of Medicine, Fetal Alcohol and Drug Unit.

U.S. Department of State, Office of Children's Issues. (2013). FY 2012 Annual Report on Intercountry Adoption, January $2013 . \quad$ Retrieved from http://adoption.state.gov/content/pdf/fy2012_annual_rep ort.pdf

U.S. Department of State, Office of Children's Issues. (2012). About us: Statistics. Retrieved from http://adoption.state.gov/about_us/statistics.php

Van der Kolk, B. A. (2003). The neurobiology of childhood trauma and abuse. Child and Adolescent Psychiatric Clinic of North America. 12, 293-317.

Van der Kolk, B. A. (2005). Developmental Trauma Disorder. Psychiatric Annals, 35, 401-408.

Vygotsky, L. S. (1993). The collected works of L. S. Vygotsky. Volume 2: The Fundamentals of Defectology (Abnormal Psychology and Learning Disabilities). R. W. Rieber, \& A. S. Carton (Eds.). New York, NY, United States: Plenum Press.

Welsh, J., Andres, G., Viana, A., Petrill, S., \& Mathias, M. (2007). Interventions for internationally adopted children and families: A review of the literature. Child and Adolescent Social Work Journal, 24, 18-31. 